\title{
Investigation of rail defects using an ultrasonic inspection method: a case study of Aksaray-Airport Light Rail Transit Line in Istanbul
}

\author{
H. Y1lmaz \& Z. Öztürk \\ Department of Civil Engineering, Istanbul Technical University, Turkey
}

\begin{abstract}
Both ballasted and non-ballasted railway superstructures have been highly affected by the increased traffic on railway lines, heavier axle loads and higher train speeds. These forces acting on rails can lead to rail damage that may cause derailments. Therefore, non-destructive inspection of rails has become more important. The primary purpose of this study is to detect rail defects using an ultrasonic inspection method on Aksaray-Airport Light Rail Transit Line which has a daily ridership of 320,000 passengers. Besides, this study aims to determine the characteristics of rail defects and to investigate the behaviour of defects on different rail welding types used on the track. Detection of rail defects is performed by an ultrasonic inspection car including ultrasonic probes which are capable of producing, transmitting and receiving ultrasonic waves that inspect the entire rail section. Ultrasonic probes enable the determination of basic characteristics of defects. Results of the ultrasonic inspection are evaluated on the basis of successive track sections between the stations in the track. In every track section, the "number of rail defects per $\mathrm{km}$ " is calculated and the distribution of defects in rail and rail welds is analysed comparatively. According to the results of ultrasonic inspection, the majority of rail defects are found to occur at rail welds. The "number of rail defects per $\mathrm{km}$ " in aluminothermic welded track sections is higher than the "number of rail defects per $\mathrm{km}$ " in flash-butt welded track sections. Besides, the defect rate in aluminothermic welds is higher than the defect rate in flash-butt welds. Although
\end{abstract}


the majority of aluminothermic weld defects occur in the head region of the weld, the majority of flash-butt weld defects arise in the web region of the weld. Keywords: rail defects, alumino-thermic weld defects, flash-butt weld defects, ultrasonic inspection method.

\section{Introduction}

The significant increase in axle loads, train speeds and railway traffic density has caused rail defects to appear in greater variety and frequency than in the past, as stated by Kumar et al. [1]. Rail failures have been classified in several different ways. According to Cannon et al. [2], there are three broad families of flaws: rail manufacturing defects, improper use or handling defects and rail fatigue defects. Rail manufacturing defects are generally inclusions of non-metallic origin or wrong local mixings of the rail steel components which generate local concentration of stresses under operating loads. A classic example of this kind of rail failure is tache oval that usually takes place in the rail head. Defects originating from improper use or handling of rails generally occur due to spinning of train wheels on rails or sudden train brakes. Wheelburn defect is a common example of this type of rail flaw. Rail fatigue failures are caused by the exhaustion of the rail steel's inherent resistance to fatigue damage. They arise from the combination of high normal and tangential stresses between wheel and rail, which causes severe shearing of the surface layer of the rail. Zumpano and Meo [3] indicate that gauge corner cracks, head checks, squats and shelling are the fundamental types of rail fatigue defects. In addition to this, rail flaws developing during rail welding process pose a considerable problem for the railway safety. Papaelias et al. [4] clarify that failures in rail welds including shrinkage cavities, inclusion, porosity and coarse dendrite microstructure adversely influence the structural integrity and fatigue performance of rail welds.

Rail imperfections which cannot be detected in the track propagate in the vertical, horizontal and longitudinal directions under traffic loads in the course of time. The majority of these defects can develop into rail breaks if left undetected. Rail fractures are one of the main reasons of the derailment of vehicles. Kumar et al. [1] explain that derailments can lead to catastrophic consequences such as loss of human lives, assets, company trust and reputation, as well as fines, compensation, traffic delay and reconstruction costs.

In order to avoid rail fractures and derailments, rails are systematically inspected for flaws using various non-destructive testing (NDT) methods. During the manufacturing process, rails are tested by automated optical cameras, ultrasonic transducers and eddy current sensing systems. Similarly, ultrasonic transducers, magnetic induction sensors, eddy current sensors and radiographic inspection have been extensively used for the inspection of rails in-service. Furthermore, novel NDT techniques including electromagnetic acoustic transducers, laser ultrasonics, guided waves and alternating current field measurement probes are under development for application in the rail industry, as stated by Papaelias et al. [4]. Many studies have been conducted so as to investigate rail failures by using a great variety of NDT methods [5-9]. 
The aim of this study is to detect rail flaws and determine the characteristics of defects on Aksaray-Airport Light Rail Transit Line which is one of the busiest railway lines in Istanbul. In order to reveal faulty rails, an ultrasonic inspection car carrying ultrasonic probes was used. According to the results of the ultrasonic inspection, "number of rail defects per km" was calculated for every track section between the stations in the track. Besides, distribution of flaws in rail and rail welds was analysed comparatively. In addition to this, the behaviours of rail failures on different rail welding types used in the track including alumino-thermic welds and flash-butt welds were investigated.

\section{Ultrasonic inspection method}

Song et al. [10] indicate that ultrasonic inspection method is one of the most commonly used NDT techniques all over the world due to its quickness, high reliability and success in flaw detection. Ultrasonic testing is fundamentally based on the generation, transmission and reception of ultrasonic waves passing through the test material. Papaelias et al. [4] explain that ultrasonic waves are produced by ultrasonic probes which utilize the frequencies ranging from $0.1 \mathrm{MHz}$ to $25 \mathrm{MHz}$. During the inspection process, ultrasonic waves are transmitted into the rail and scan the entire rail section. Ultrasonic waves reflect from an interface, such as the base of the rail or a defect within the rail. Ultrasonic probes receive the reflected waves again. The amplitude and arrival time of the reflected waves can provide significant information about the location of the defects within the rail. Ultrasonic testing of rails is carried out either manually using portable equipment or special test vehicles including ultrasonic probes.

In this work, defective rails on Aksaray-Airport Light Rail Transit Line were identified by an ultrasonic inspection car operating at an average speed of $5 \mathrm{~km} / \mathrm{h}$. Ultrasonic inspection car involved 6 ultrasonic probes for per rail, thus 12 probes in total carried out the inspection process. In Figure 1, the ultrasonic inspection car is shown.

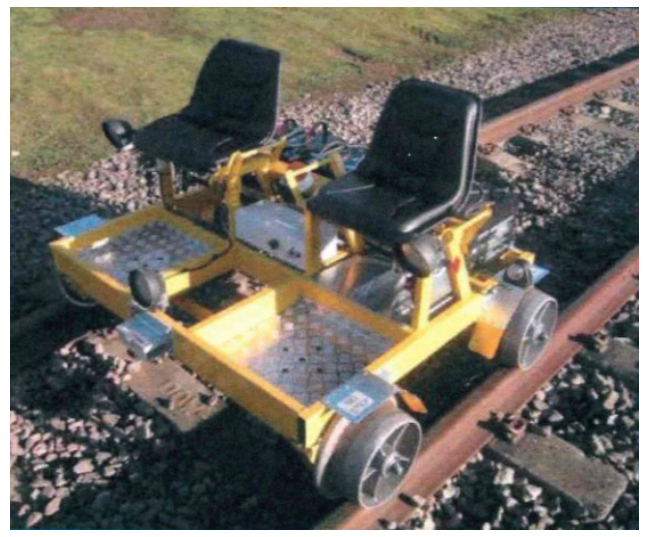

Figure 1: Ultrasonic inspection car. 
Both rails on the track were inspected simultaneously by the ultrasonic probes having a frequency of $2.5 \mathrm{MHz}$. Ultrasonic probes were capable of checking the rail head, rail web and rail foot for the flaws. Figure 2 presents the ultrasonic probes within the ultrasonic test car.

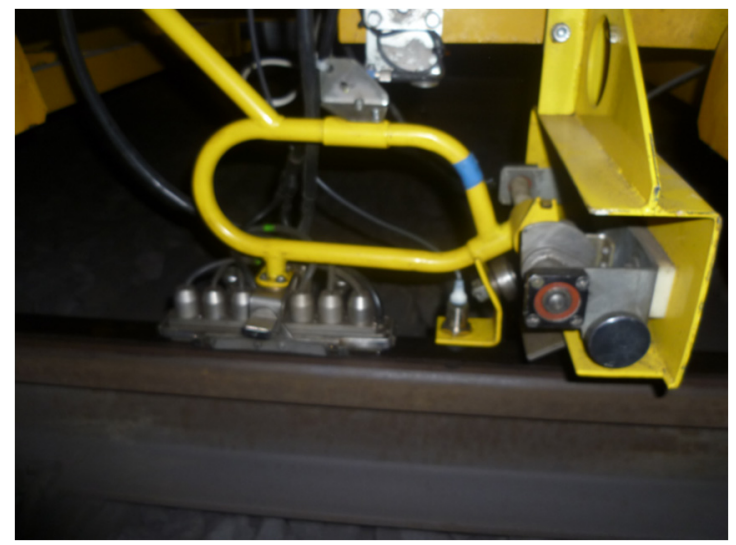

Figure 2: Ultrasonic probes within the inspection car.

In order to increase the probability of detection of defects located in different parts of the rail, ultrasonic waves were transmitted into the rail at various incident angles. According to user manual of the inspection car, angles of the probes were $0^{\circ}, 42^{\circ}, 58^{\circ}$ and $70^{\circ}[11]$. $0^{\circ}$ probe and $42^{\circ}$ probe performed the ultrasonic test throughout the rail section including rail head, web and foot. On the other hand, $58^{\circ}$ probe and $70^{\circ}$ probe inspected only rail head. Ultrasonic measurement of rails was conducted by 2 probe blocks and each of the blocks was composed of 3 ultrasonic probes (as shown in Figure 3).

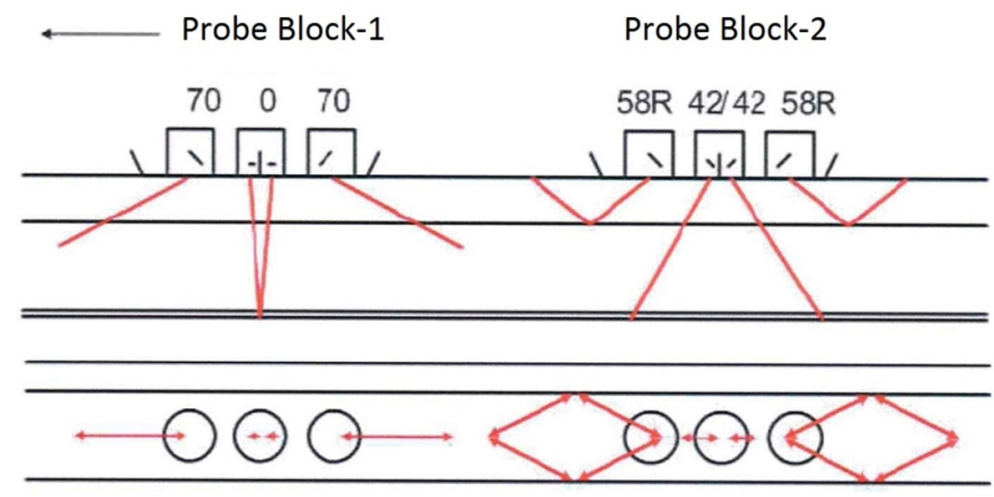

Figure 3: Schematic representation of ultrasonic probes. 


\section{Results of ultrasonic inspection on the track}

The study area where ultrasonic measurement of rails was performed is AksarayAirport Light Rail Transit Line in Istanbul. The first part of this rail line was put into service in 1989 and the line took its final form with the construction of new track sections in 2002. The rail line which has a daily ridership of 320000 passengers consists of 18 stations. Y1lmaz [12] states that while 9 of the stations are built as ground station facilities, 6 of the stations are located in tunnel and 3 of the stations are located in viaduct. The rail track has the length of $19.6 \mathrm{~km}$. Total length of the tunnels in the track is $5000 \mathrm{~m}$ while the total length of the viaducts is $2530 \mathrm{~m}$. For this rail line, minimum value of horizontal curve radius is $275 \mathrm{~m}$ and maximum value of superelevation is $140 \mathrm{~mm}$.

Superstructure of Aksaray-Airport Light Rail Transit Line includes both ballasted and non-ballasted track features. Although most of the line is built as a ballasted track, a small part of the line is constructed as a non-ballasted track. The structure of the ballast layer is based on limestone and basalt. Rails used in the track are in accordance with European Standard EN 13674-1. Rail profiles are 49E1 and steel grade is R260. In the track, continuous welded rails involving alumino-thermic rail welds and flash-butt rail welds are used. Concrete sleepers together with wooden sleepers are utilized. Maximum speed of the trains used in the track is $80 \mathrm{~km} / \mathrm{h}$ while the maximum value of the axle load is $80 \mathrm{kN}$.

Results of the ultrasonic inspection were evaluated on the basis of successive track sections between the stations in the track. A track section is composed of two sequential stations and the remaining part between them. In addition to this, another analysis was carried out in order to investigate the behaviours of rail defects on different rail welding types.

\subsection{Evaluation of results on the basis of track sections}

Track section between Aksaray Station and Emniyet Station is the first track section that was analysed. This part of the track consisting of alumino-thermic rail welds has the length of $1089 \mathrm{~m}$. According to the results of the ultrasonic inspection, 45 rail failures were detected in this section. Therefore, number of rail defects per $\mathrm{km}$ was calculated as 41.32 defect $/ \mathrm{km}$. While 38 of detected rail flaws were found in rail welds, 7 of them were located in rail. In other words, $84.44 \%$ of rail faults occurred in rail welds as $15.56 \%$ of them developed in rail. Number of alumino-thermic welds in this track section was 121 and 38 of them were found to be defective, which means that $31.40 \%$ of the welds contained flaws.

The second track section is between Emniyet Station and Ulubatli Station. This track section composing of alumino-thermic rail welds has the length of $1187 \mathrm{~m}$. At the end of the ultrasonic inspection, number of rail defects detected in this part was 31 . Thus, number of rail defects per $\mathrm{km}$ was computed as $26.12 \mathrm{defect} / \mathrm{km}$. Although 24 of rail imperfections appeared in rail welds, 7 of them arose in rail. To put it another way, $77.42 \%$ of rail flaws developed in rail welds while $22.58 \%$ of them took place in rail. There were 131 alumino-thermic 
welds in this track section and 24 of them involved defects, showing that $18.32 \%$ of the welds were faulty.

The following track section between Ulubatli Station and Bayrampasa Station has the length of $1561 \mathrm{~m}$. This part of the track comprises not only aluminothermic rail welds but also flash-butt welds. Length of the alumino-thermic welded track section is $425 \mathrm{~m}$ as the length of the flash-butt welded section is $1136 \mathrm{~m}$. As a result of the ultrasonic inspection, 9 rail failures were identified, thus the number of rail defects per $\mathrm{km}$ was determined as $5.76 \mathrm{defect} / \mathrm{km}$. Despite the fact that 7 of rail flaws existed in rail welds, 2 of them were located in rail. This result reveals that $77.78 \%$ of rail imperfections occurred in rail welds as $22.22 \%$ of them arose in rail. Total number of rail welds (both aluminothermic welds and flash-butt welds) in this track section was 189 and 7 of them were faulty, indicating that $3.70 \%$ of the welds were flawed. For more detailed analysis, defect rate in alumino-thermic welds and flash-butt welds was determined separately. 5 of 47 alumino-thermic welds included flaws, meaning that $10.64 \%$ of the alumino-thermic welds were unsound. In addition, 2 of 142 flash-butt welds contained failures, meaning that $1.41 \%$ of the flash-butt welds were defective.

Track section between Bayrampasa Station and Sagmalcilar Station is $1529 \mathrm{~m}$ long. This part of the track is constructed with flash-butt rail welds. According to the results of the ultrasonic test, number of rail imperfections detected in this section was 17. As a consequence, number of rail defects per km was computed as $11.12 \mathrm{defect} / \mathrm{km}$. In spite of the fact that 12 of rail failures appeared in rail welds, 5 of them took place in rail. In other words, $70.59 \%$ of rail flaws developed in rail welds while $29.1 \%$ of them occurred in rail. There were 191 flash-butt welds in this track section and 12 of them were imperfect, indicating that $6.28 \%$ of the welds were faulty.

The subsequent track section between Sagmalcilar Station and Kocatepe Station has the length of $1662 \mathrm{~m}$. This track section contains flash-butt welds. At the end of the ultrasonic measurement, 5 rail flaws were discovered. Therefore, number of rail defects per $\mathrm{km}$ was calculated as $3.01 \mathrm{defect} / \mathrm{km}$. All of the rail failures occurred in rail welds. In this region, number of flash-butt welds was 207 and 5 of them were flawed, meaning that $2.2 \%$ of the welds were defective.

The ensuing track section is between Kocatepe Station and Otogar Station. This part of the track involving flash-butt welds has the length of $1193 \mathrm{~m}$. Ultrasonic inspection of rails resulted in the detection of 7 rail imperfections. Thus, number of rail defects per $\mathrm{km}$ was determined as $5.87 \mathrm{defect} / \mathrm{km}$. While 5 of rail faults developed in rail welds, 2 of them arose in rail. To put it another way, $71.43 \%$ of rail failures were found in rail welds as $28.57 \%$ of them were located in rail. There were 149 flash-butt welds in this track region and 5 of them contained flaws, showing that $3.36 \%$ of the welds were unsound.

Track section between Otogar Station and Terazidere Station is $1250 \mathrm{~m}$ long. This region of the track consists of flash-butt welds. Ultrasonic testing of rails was concluded with the discovery of 15 rail failures. As a result, number of rail defects per $\mathrm{km}$ was computed as $12.00 \mathrm{defect} / \mathrm{km}$. Even though 14 of rail imperfections occurred in rail welds, one of them took place in rail. It means that 
$93.33 \%$ of rail flaws existed in rail welds as $6.67 \%$ of them were situated in rail. In this track section, number of flash-butt welds was 156 and 14 of them were defective, indicating that $8.97 \%$ of the welds were faulty.

The following track section between Terazidere Station and Davutpasa Station has the length of $1202 \mathrm{~m}$. This region is constructed with flash-butt welds. Results of the ultrasonic measurement presented that there were 14 rail defects in this section. Number of rail defects per $\mathrm{km}$ was calculated as 11.65 defect $/ \mathrm{km}$. Although 13 of rail flaws were found in rail welds, one of them was located in rail. It signifies that $92.86 \%$ of rail failures appeared in rail welds while $7.14 \%$ of them developed in rail. This track section included 150 flash-butt welds and 13 of them were flawed, meaning that $8.67 \%$ of the welds were imperfect.

The ensuing track section between Davutpasa Station and Merter Station is $1624 \mathrm{~m}$ long. This region of the track comprises flash-butt welds. As a result of the ultrasonic inspection, 11 rail flaws were identified and the number of rail defects per $\mathrm{km}$ was determined as $6.77 \mathrm{defect} / \mathrm{km}$. All of the rail imperfections were located in rail welds. In this track section, there were 203 flash-butt welds and 11 of them contained failures, signifying that $5.42 \%$ of the welds were defective.

Track section between Merter Station and Zeytinburnu Station has the length of $1028 \mathrm{~m}$. In this part of the track, flash-butt welds are used. At the end of the ultrasonic test, only one rail flaw was discovered. Thus, number of rail defects per $\mathrm{km}$ was computed as $0.97 \mathrm{defect} / \mathrm{km}$. Detected rail failure was found in a rail weld. This track section involved 128 flash-butt welds and one of them was flawed, implying that $0.78 \%$ of the welds were unsound.

The subsequent track section between Zeytinburnu Station and Bakirkoy Station is $1455 \mathrm{~m}$ long. This segment of the track contains flash-butt welds together with alumino-thermic welds. Length of the flash-butt welded track section is $1355 \mathrm{~m}$ while length of the alumino-thermic welded track section is $100 \mathrm{~m}$. As a consequence of the ultrasonic measurement, 3 rail imperfections were identified in the whole of the track section. Accordingly, number of rail defects per $\mathrm{km}$ was calculated as $2.06 \mathrm{defect} / \mathrm{km}$. All of the rail failures arose in rail, showing that none of the rail welds involved flaws. Defect rate of aluminothermic welds and flash-butt welds was 0 .

The following track section between Bakirkoy Station and Bahcelievler Station is $1157 \mathrm{~m}$ long. This region is composed of alumino-thermic welds. According to the results of the ultrasonic inspection, 2 rail failures were revealed. Therefore, number of rail defects per $\mathrm{km}$ was determined as $1.73 \mathrm{defect} / \mathrm{km}$. All of the rail imperfections occurred in rail, which means that none of the aluminothermic welds included flaws. In other words, ratio of the defective welds in this section was 0 .

Track section between Bahcelievler Station and Atakoy Station has the length of $1665 \mathrm{~m}$. In this part of the track, not only alumino-thermic welds but also flash-butt welds are used. Alumino-thermic welded track section is $578 \mathrm{~m}$ long while flash-butt welded track section is $1087 \mathrm{~m}$ long. Ultrasonic testing of rails resulted in the discovery of 2 rail failures. Thus, number of rail defects per $\mathrm{km}$ 
was calculated as $1.20 \mathrm{defect} / \mathrm{km}$. All of the rail flaws were found in rail welds. Total number of rail welds (both alumino-thermic welds and flash-butt welds) in this track section was 199 and 2 of them were defective, showing that $1.00 \%$ of rail welds were flawed. For more comprehensive analysis, defect rate of alumino-thermic welds and flash-butt welds was determined independently. All of the rail failures arose in flash-butt welds, so defect rate of alumino-thermic welds was 0 . However, 2 of 135 flash-butt welds contained flaws, signifying that $1.48 \%$ of the flash-butt welds were unsound.

The ensuing track section located between Atakoy Station and Yenibosna Station is $890 \mathrm{~m}$ long. This part of the track consists of flash-butt welds. Ultrasonic testing of rails was concluded with the detection of 9 rail flaws. Accordingly, number of rail defects per $\mathrm{km}$ was computed as $10.11 \mathrm{defect} / \mathrm{km}$. All of the rail failures took place in rail welds. There were 111 flash-butt welds in the related track section and 9 of them were faulty, indicating that $8.11 \%$ of the welds were imperfect.

The subsequent track section is between Yenibosna Station and Word Trade Centre (DTM) Station. This track section involving flash-butt welds has the length of $858 \mathrm{~m}$. Ultrasonic inspection of rails resulted in the discovery of 3 rail failures. Thus, number of rail defects per $\mathrm{km}$ was calculated as $3.49 \mathrm{defect} / \mathrm{km}$. All of the rail flaws arose in rail welds. This part of the track contained 107 flash-butt welds and 3 of them were flawed, implying that $2.80 \%$ of the welds were defective.

The last track section between DTM Station and Airport Station is $1281 \mathrm{~m}$ long. This region of the track includes flash-butt welds. As a result of the ultrasonic measurement, 3 rail failures were identified. Therefore, number of rail defects per $\mathrm{km}$ was determined as 2.34 defect $/ \mathrm{km}$. Although 2 of rail flaws appeared in rail, one of them developed in rail weld. In other words, $66.67 \%$ of rail defects were found in rail as $33.33 \%$ of them existed in rail welds. There were 160 flash-butt welds in this track section and one of them was faulty, showing that $0.62 \%$ of the welds were unsound.

For every sequential track section, results of the ultrasonic inspection are summarized in Table 1. Table 1 provides information about number of rail defects per $\mathrm{km}$, distribution of rail defects and ratio of defective rail welds in every track section.

\subsection{Evaluation of results on the basis of different rail welding types}

In order to analyze the behaviours of rail defects on various rail welding types, results of the ultrasonic measurement in alumino-thermic welded track section and flash-butt welded section were evaluated separately. Total length of the alumino-thermic welded part of the track is $4052 \mathrm{~m}$. According to the results of the ultrasonic examination, 78 rail flaws were detected in the alumino-thermic welded section. Therefore, number of rail defects per $\mathrm{km}$ was calculated as 19.25 defect $/ \mathrm{km}$. Despite the fact that 65 of rail failures occurred in rail welds, 13 of them arose in rail. To put it another way, $83.33 \%$ of rail imperfections appeared in rail welds as $16.67 \%$ of them existed in rail. This part of the track is composed of 450 alumino-thermic welds and 65 of them were faulty, implying that the ratio 
of defective welds was $14.44 \%$. For more detailed analysis, the nature of alumino-thermic weld defects was investigated. While 47 of flaws were found in the head region of the weld, 18 of them were located in the web region. This result shows that $72.31 \%$ of failures developed in the head region while $27.69 \%$ of them arose in the web region of the weld.

Flash-butt welded track section is $15001 \mathrm{~m}$ long. As a consequence of the ultrasonic inspection, 84 rail imperfections were identified in the flash-butt welded segment. Thus, number of rail defects per $\mathrm{km}$ was computed as 5.60 defect $/ \mathrm{km}$. In spite of the fact that 71 of rail flaws appeared in rail welds, 13 of them took place in rail. In other words, $84.52 \%$ of rail failures occurred in rail welds as $15.48 \%$ of them developed in rail. This segment of the track consists of 1875 flash-butt welds and 71 of them were flawed, signifying that the ratio of defective welds was $3.79 \%$. For more comprehensive assay, the nature of flashbutt weld defects was examined. Although 43 of faults arose in the web region of the weld, 28 of them were found in the head region. This result shows that $60.56 \%$ of flaws were located in the web region while $39.44 \%$ of them occurred in the head region of the weld.

Table 1: Evaluation of results on the basis of track sections.

\begin{tabular}{|c|c|c|c|c|}
\hline \multirow{2}{*}{ Track section } & \multirow{2}{*}{$\begin{array}{c}\text { Number of rail } \\
\text { defects per km }\end{array}$} & \multicolumn{2}{|c|}{ Distribution of defects } & $\begin{array}{c}\text { Ratio of } \\
\text { defective rail } \\
\text { welds (\%) }\end{array}$ \\
\cline { 3 - 5 } & & Rail (\%) & Rail weld (\%) & 31.40 \\
\hline Aksaray-Emniyet & 41.32 & 15.56 & 84.44 & 18.32 \\
\hline Emniyet-Ulubatli & 26.12 & 22.58 & 77.42 & 3.70 \\
\hline Ulubatli-Bayrampasa & 5.76 & 22.22 & 77.78 & 6.28 \\
\hline Bayrampasa-Sagmalcilar & 11.12 & 29.41 & 70.59 & 2.42 \\
\hline Sagmalcilar-Kocatepe & 3.01 & 0.00 & 100.00 & 3.36 \\
\hline Kocatepe-Otogar & 5.87 & 28.57 & 71.43 & 8.97 \\
\hline Otogar-Terazidere & 12.00 & 6.67 & 93.33 & 8.67 \\
\hline Terazidere-Davutpasa & 11.65 & 7.14 & 92.86 & 5.42 \\
\hline Davutpasa-Merter & 6.77 & 0.00 & 100.00 & 0.78 \\
\hline Merter-Zeytinburnu & 0.97 & 0.00 & 100.00 & 0.00 \\
\hline Zeytinburnu-Bakirkoy & 2.06 & 100.00 & 0.00 & 0.00 \\
\hline Bakirkoy-Bahcelievler & 1.73 & 100.00 & 0.00 & 1.00 \\
\hline Bahcelievler-Atakoy & 1.20 & 0.00 & 100.00 & 8.11 \\
\hline Atakoy-Yenibosna & 10.11 & 0.00 & 100.00 & 2.80 \\
\hline Yenibosna-DTM & 3.49 & 0.00 & 100.00 & 0.62 \\
\hline DTM-Airport & 2.34 & 66.67 & 33.33 & \\
\hline
\end{tabular}

Table 2 provides information about the evaluation based upon the aluminothermic and flash-butt welded track sections. For both alumino-thermic and flash-butt welded track segments, number of rail defects per $\mathrm{km}$, ratio of defective rail welds and location of weld defects are summarized in Table 2. 
Table 2: Evaluation of results on the basis of different rail welding types.

\begin{tabular}{|c|c|c|c|c|}
\hline \multirow{2}{*}{ Track section } & \multirow{2}{*}{$\begin{array}{c}\text { Number of rail } \\
\text { defects per km }\end{array}$} & \multicolumn{2}{|c|}{ Location of weld defects } & $\begin{array}{c}\text { Ratio of } \\
\text { defective rail } \\
\text { welds (\%) }\end{array}$ \\
\cline { 3 - 4 } & & Head (\%) & Web (\%) & 14.44 \\
\hline $\begin{array}{c}\text { Alumino-thermic } \\
\text { welded section }\end{array}$ & 19.25 & 72.31 & 27.69 & 3.79 \\
\hline $\begin{array}{c}\text { Flash-butt } \\
\text { welded section }\end{array}$ & 5.60 & 39.44 & 60.56 & \\
\hline
\end{tabular}

\section{Conclusion}

In this study, rail failures in Aksaray-Airport Light Rail Transit Line were detected by ultrasonic test method and basic characteristics of rail flaws were investigated. Ultrasonic measurement of rails was conducted by an ultrasonic inspection car carrying 12 ultrasonic probes. According to the results of the ultrasonic inspection, number of rail defects per $\mathrm{km}$ reached the maximum value in the track section between Aksaray Station and Emniyet Station. It was followed by the track section between Emniyet Station and Ulubatli Station where number of rail defects per $\mathrm{km}$ got the second highest value. The common feature of these track segments was that they were constructed with aluminothermic rail welds. On the other hand, number of rail defects per km was lowest in the track section between Merter Station and Zeytinburnu Station, which contained flash-butt rail welds.

Evaluation of results on the basis of track sections revealed that distribution of rail flaws was concentrated at rail welds. In $81.25 \%$ of 16 track sections, the majority of rail failures were located in rail welds. This is because welding material has different material properties from the rail. Rail welding has distinctive mineral composition and grain structure. Consequently, rail welds cannot have enough strength to meet impact forces, frictional stresses and shear stresses.

Results of the ultrasonic test showed that number of rail defects per $\mathrm{km}$ in alumino-thermic welded track part was $19.25 \mathrm{defect} / \mathrm{km}$ while number of rail defects per $\mathrm{km}$ in flash-butt welded part was $5.60 \mathrm{defect} / \mathrm{km}$. Accordingly, the number of rail defects per $\mathrm{km}$ in the alumino-thermic welded section was equal to approximately 3.44 times the number of rail defects per $\mathrm{km}$ in the flash-butt welded section. In addition to this, ratio of imperfect alumino-thermic welds was $14.44 \%$ as the ratio of imperfect flash-butt welds was $3.79 \%$. Therefore, the ratio of defective alumino-thermic welds was equal to 3.81 times the ratio of defective flash-butt welds. As a result, alumino-thermic welds were thought to perform worse than the flash-butt welds. The reason why alumino-thermic welds included more failures than flash butt welds was the structural characteristics of the alumino-thermic welds. In alumino-thermic rail welding, a different material called thermit is used to joint rail ends. Thermit, which is a mixture of iron oxide 
and aluminium powder, produces the superheated molten steel and generates the rail weld. However, a decrease in stiffness occurs in the transition zone of the weld due to material difference. Thus, quality of the alumino-thermic weld decreases. On the other hand, flash-butt welding of rails does not contain any materials other than rail. As a result, quality of the flash-butt welds increases. Furthermore, faulty workmanship is more common in alumino-thermic welding process as it mainly depends on the manual labour.

In the final analysis, locations of alumino-thermic and flash butt weld defects were investigated. For the alumino-thermic welds, most of rail faults developed in the head region of the weld. However, for the flash-butt welds, the majority of rail failures appeared in the web region of the weld.

\section{References}

[1] Kumar, S., Gupta, S., Ghodrati, B. \& Kumar, U., An approach for risk assessment of rail defects. International Journal of Reliability, Quality and Safety Engineering, 17(4), pp. 291-311, 2010.

[2] Cannon, D.F., Edel, K.O., Grassie, S.L. \& Sawley, K., Rail defects: an overview. Fatigue \& Fracture of Engineering Materials \& Structures, 26, pp. 865-886, 2003.

[3] Zumpano, G. \& Meo, M., A new damage detection technique based on wave propagation for rails. International Journal of Solids and Structures, 43, pp. 1023-1046, 2006.

[4] Papaelias, M.P., Roberts, C. \& Davis, C.L., A review on non-destructive evaluation of rails: state-of-the-art and future development. Proceedings of the Institution of Mechanical Engineers, Part F: Journal of Rail and Rapid Transit, 222, pp. 367-384, 2008.

[5] Hesse, D. \& Cawley, P., Defect detection in rails using ultrasonic surface waves. Insight, 49, pp. 318-326, 2007.

[6] Fan, Y., Dixon, S., Edwards, R.S. \& Jian, X., Ultrasonic surface wave propagation and interaction with surface defects on rail track head. NDT\&E International, 40, pp. 471-477, 2007.

[7] Thomas, H.M., Dey, A. \& Heyder, R., Eddy current test method for early detection of rolling contact fatigue (RCF) in rails. Insight, 52, pp. 361$365,2010$.

[8] Thomas, H.M., Heckel, T. \& Hanspach, G., Advantage of a combined ultrasonic and eddy current examination for railway inspection trains. Insight, 49, pp. 341-344, 2007.

[9] Haidemenopoulos, G.N., Zervaki A.D., Terezakis P., Tzanis, J., Giannakopoulos, A.E. \& Kotouzas, M.K., Investigation of rolling contact fatigue cracks in a grade $900 \mathrm{~A}$ rail steel of a metro track. Fatigue Fract. Engng. Mater. Struct., 29, pp. 887-900, 2006.

[10] Song, Z., Yamada, T., Shitara, H. \& Takemura, Y., Detection of damage and crack in railhead by using eddy current testing. Journal of Electromagnetic Analysis and Applications, 3, pp. 546-550, 2011. 
[11] Geismar (UK) Limited, User manual of Ego-Us ultrasonic inspection car. Northampton, 2009.

[12] Y1lmaz, H., Investigation of rail flaws by using ultrasonic method on model track and determination of rail stresses. Master Thesis, Istanbul Technical University, Graduate School of Science, Engineering and Technology, Istanbul, 2014. 